\title{
Milk replacer restriction during early life impairs the live body weight and progesterone patterns of ewe lambs during the replacement period
}

\author{
A. Santos, ${ }^{*}$ F. J. Giráldez, ${ }^{*}$ C. Valdés, ${ }^{*}$ E. Trevisi,† L. Lucini,ł J. Frutos, ${ }^{*}$ and S. Andrés*¹ \\ *Instituto de Ganadería de Montaña (CSIC-Universidad de León), Finca Marzanas s/n, 24346, Grulleros, León, Spain \\ †Department of Animal Sciences, Food and Nutrition (DIANA), and \\ fDepartment for Sustainable Food Process, Università Cattolica del Sacro Cuore, Via Emilia Parmense 84, 29122, Piacenza, Italy
}

\section{ABSTRACT}

Nutritional programming caused by feed restriction during the early life may counteract the profitability of the dairy sheep farm. However, most studies have been focused exclusively on the prenatal period, and scarce information regarding the effect of milk replacer (MR) restriction on feed efficiency [residual feed intake (RFI)] and progesterone patterns of replacement ewe lambs is available. Therefore, in the present study 40 Assaf female newborn lambs were penned individually and assigned randomly to 1 of 2 treatment groups $(\mathrm{n}=$ 20 per treatment). The first group of lambs was fed MR ad libitum (ADLB), whereas the second one (restricted, RES) only received approximately $62.5 \%$ of the MR intake measured in the ADLB group. All the lambs were weighed twice a week until they were $35 \mathrm{~d}$ old. Then 8 lambs from each group were killed and a morphological study of the gut was performed. Moreover, a piece of liver was cut to measure fat content and oxidative status. The rest of the ewe lambs (24) were weaned and offered a total mixed ration ad libitum to calculate the RFI during the replacement phase. Plasma samples were collected when ewe lambs were 8 mo old to perform a nontargeted metabolomic analysis on a hybrid quadrupole-time-of-flight mass spectrometer coupled to an ultra-high-performance liquid chromatographic system. Progesterone was also measured weekly on serum samples by sequential competitive immunoassay until the end of the experiment (9.5 mo old). The results observed indicate that moderated MR restriction promoted differences in the morphology of the gut of the 35-d-old lambs, but not in the apparent digestibility or feed efficiency traits (RFI) during the replacement phase. However, there was a trend toward reduced live body weight of the RES ewe lambs when they were 9.5

Received February 26, 2018.

Accepted May 16, 2018.

${ }^{1}$ Corresponding author: sonia.andres@eae.csic.es mo old. Moreover, progesterone patterns revealed that only 1 RES versus 4 ADLB ewe lambs had ovulated for the first time at the end of the experiment. This evidence suggests the existence of long-term effects caused by early feed restriction with negative consequences on live body weight and reproductive traits of replacement ewe lambs.

Key words: feed efficiency, puberty, nutritional programming, metabolome

\section{INTRODUCTION}

Insufficient nutrient supply to replacement ewe lambs during the first weeks of life may counteract the flock output and profitability of the dairy sheep farm as a consequence of the early nutritional programming caused by early feed restriction (Robinson, 1996). In fact, the development of the mammary parenchymal mass in calves is affected by the feeding level during the first weeks of life (Kaske et al., 2010) and hence the milk yield mainly during the first lactation (Drackley et al., 2007). Moreover, previous studies in fattening lambs have demonstrated that early feed restriction enhances fat accretion, thus impairing feed efficiency (FE) and increasing feeding costs to reach a similar target BW at slaughter (Santos et al., 2018a,b,c). However, there is a lack of studies describing the effects of early feed restriction on replacement ewe lambs, a circumstance that might take place when environmental, health, and feeding conditions are not optimal.

In this sense, a very widespread measure of $\mathrm{FE}$ is residual feed intake (RFI), which is defined as the difference between an animal's actual feed intake and its expected feed intake based on its size and growth (Koch et al., 1963). It is independent of the level of production, and the lower the value the more efficient the animal is. Residual feed intake has been described to be negatively influenced by several factors such as genetic traits, nutrition of the pregnant dam, and early postnatal nutrition (Gotoh, 2015; Bell and Greenwood, 2016). Nevertheless, divergent results can be observed 
attending to different levels or periods of restriction or realimentation, diet types administered during the refeeding period (more or less energetic), or the characteristics (age or sex) of the animals studied (Neto et al., 2011). Furthermore, the length of the unproductive replacement phase before the ewe lambs reach sexual maturity can be extended in early-feed-restricted animals (Chilliard et al., 1998; Robinson et al., 2002, 2005), but the mechanisms explaining the residual effects after a long refeeding period are largely unknown. Therefore, studies describing the effects of milk replacer (MR) restriction on replacement ewe lambs are required to adequately evaluate the effects on animal performance and reproductive traits. These studies should include -omic tools to better understand the metabolic pathways impaired by feed restriction (Carrillo et al., 2016; Santos et al., 2018c), thus helping to identify potential strategies to correct detrimental effects during the replacement period.

The purpose of this experiment was to determine the effect of MR restriction of replacement ewe lambs on both FE traits and progesterone patterns during the replacement period to establish if the RFI or reproductive traits are negatively affected (or not) according to this factor. A metabolomic approach has been used to better understand the biochemical mechanisms under the observed effects.

\section{MATERIALS AND METHODS}

\section{Care and Use of Animals}

All handling practices involving animals followed the recommendations of the Directive 2010/63/EU of the European Parliament and of the Council on the protection of animals used for scientific purposes and the Instituto de Ganadería de Montaña, Animal Experimentation Committee (protocol number 2015-04).

\section{Animals and Diets}

A flock of newborn Assaf lambs was separated from their dams just after parturition. The dams were handmilked and the colostrum offered by bottle-feeding for 2 d. Lambs were bottle-fed for another $2 \mathrm{~d}$ with commercial MR (Cordevit, Leches Maternizadas S.A., León, Spain). All newborn lambs were treated with an intramuscular injectable selenium + vitamin E complex at the prescribed dose (Vitasel: $5 \mathrm{~g}$ of $\alpha$-tocopherol acetate, $110 \mathrm{mg}$ of sodium selenite, excipient, per 100 $\mathrm{mL}$; Laboratorios Ovejero, León, Spain) to prevent nutritional muscular dystrophy (white muscle disease). Thereafter, 40 female lambs were selected from the
Table 1. Ingredients and chemical composition of the commercial lamb milk replacer administered during the artificial rearing period of the lambs

\begin{tabular}{lr}
\hline Item & Value \\
\hline Ingredient (g/kg) & \\
Skim milk powder & 500 \\
Milk whey powder & 160 \\
Vegetable oil (cocoa) & 140 \\
Animal fat (pork lard) & 120 \\
Whey protein powder & 40 \\
Hydrolyzed wheat protein & 15 \\
Yeast/sodium bicarbonate/dextrose & 15 \\
PreVIT mineral ${ }^{1}$ & 10 \\
Chemical composition (g/kg of DM) & \\
DM (g/kg) & 960 \\
CP & 235 \\
Ether extract & 260 \\
Ash & 70 \\
ME (kcal/kg of DM) & 5,089 \\
\hline
\end{tabular}

${ }^{1}$ Provided per kilogram of milk replacer: vitamin A, 80,000 IU; vitamin $\mathrm{D}_{3}$, 4,250 IU; iron, $40 \mathrm{mg}$; cobalt, $0.2 \mathrm{mg}$; copper, $5 \mathrm{mg}$; manganese, 25 mg; zinc, $30 \mathrm{mg}$; selenium, $0.2 \mathrm{mg}$ (Leches Maternizadas S.A., León, Spain).

flock to minimize the range of both, live body weight (LBW), and day of birth. Subsequently, all the lambs were penned individually and allocated randomly to 1 of 2 treatment groups $(\mathrm{n}=20$ per treatment). All the lambs were fed MR 3 times daily (0830, 1400, and 2030 h) during the first week, and only twice daily (0830 and $1930 \mathrm{~h}$ ) during the rest of the suckling period. However, whereas the first group of lambs was fed MR ad libitum (ADLB, approximately 2.5 times maintenance energy requirements to gain $250 \mathrm{~g} / \mathrm{d}$ ), the second one (restricted, RES) only received approximately $62.5 \%$ of MR intake measured in the ADLB group (approximately 1.5 times maintenance energy requirements to gain 100-120 g/d; NRC, 1985; Giráldez et al., 1999). Ingredients and chemical composition of the MR administered are summarized in Table 1.

All the female lambs were weighed twice a week throughout the suckling period and once a week after being weaned. When lambs were $35 \mathrm{~d}$ old, 8 lambs from each group (16 lambs in total) were stunned, killed by exsanguination from the jugular vein, eviscerated, and skinned according to the Council Regulation (EC) $\mathrm{N}^{\circ}$ $1099 / 2009$ on the protection of animals at the time of killing. A piece of liver was cut and kept at $-80^{\circ} \mathrm{C}$ until fat content (AOAC International, 2003) and thiobarbituric acid reactive substances (TBARS, an indicator of oxidative stress) were measured (Bodas et al., 2012). Moreover, a piece of ileum from each animal $20 \mathrm{~cm}$ from the pylorus was placed in a $10 \%$ formaldehyde solution (Sigma-Aldrich, St. Louis, MO) and used to measure the villus height according to Makovicky et al. (2014). 
The rest of the ADLB ewe lambs $(\mathrm{n}=12)$ were weaned progressively starting at a mean LBW of 13.5 $\mathrm{kg}$ (ADLB), whereas the RES ewe lambs $(\mathrm{n}=12)$ started weaning either at $11.5 \mathrm{~kg}$ or $70 \mathrm{~d}$ old to ensure the viability of these animals. The progressive weaning lasted $1 \mathrm{wk}$ and consisted of restricting MR intake and allowing free access to a starter feed for replacement lambs (Babymix, Inatega, Spain), barley straw, and alfalfa hay. Once the animals were weaned they were moved to a single feedlot where they stayed during 42 d (first postweaning period), being fed ad libitum the same starter feed, barley straw, and alfalfa hay supplied in separate feeders. After this period, the ewe lambs were fed ad libitum a TMR (CP: $128 \mathrm{~g} / \mathrm{kg}$ of DM; ME: $2,303 \mathrm{kcal} / \mathrm{kg}$ of DM; NRC, 1985) in the feedlot until they were 7.5 mo old (end of the second postweaning period). Then, the ewe lambs were individually penned during $8 \mathrm{wk}$ (third postweaning period) trying to reach a balance between scientific purposes and welfare considerations. During this last phase the intake of TMR was measured individually to obtain data to estimate the RFI. Ingredients and chemical composition of the TMR administered are summarized in Table 2.

Animals were allowed $7 \mathrm{~d}$ of adaptation to individual pens, which were equipped with an automatic drinker to provide fresh drinking water. All the ewe lambs received ad libitum the experimental TMR at $0900 \mathrm{~h}$ daily. The amount of feed offered to each ewe lamb was adjusted daily according to the previous day's intake to allow refusals of approximately $200 \mathrm{~g} / \mathrm{kg}$ of feed offered. Samples of both the feed offered and orts were collected daily for subsequent analyses of DM content

Table 2. Ingredients (Inatega, León, Spain) and chemical composition of the TMR administered to the replacement ewe lambs

\begin{tabular}{lc}
\hline Item & Value \\
\hline Ingredient (g/kg) & 360 \\
Barley & 160 \\
Lucerne & 157 \\
Barley straw & 133 \\
Vetch & 50 \\
Molasses (sugar cane) & 50 \\
Corn & 43 \\
Sunflower & 30 \\
Soybean meal 44 & 17 \\
Vitamins and minerals & \\
Chemical composition, (g/kg of DM unless & 892 \\
otherwise indicated) & 355 \\
DM (g/kg) & 215 \\
aNDF & 128 \\
ADF & 75.4 \\
CP & 2,303 \\
Ash & \\
ME (kcal/kg of DM) & \\
\hline
\end{tabular}

${ }^{1}$ Amylase-treated neutral detergent fiber. after mixing all the subsamples refused by each animal during one week. Samples of the TMR offered were collected weekly and analyzed for DM (ISO, 1999), ash (ISO, 2002), CP (ISO, 2005), amylase-treated NDF (NDF was assayed with a heat-stable amylase and expressed inclusive of residual ash; Ankom Technology Corp., Macedon, NY), and ADF (ADF was expressed inclusive of residual ash; Ankom Technology Corp.).

\section{Animal Performance, Digestibility, and Blood Sampling}

Average daily gain $(\mathrm{g} / \mathrm{d})$ was estimated as the regression coefficient (slope) of LBW against time using the REG procedure of the SAS package (version 9.4, SAS Institute Inc., Cary, NC). The feed conversion ratio was obtained by dividing the feed intake per day by the ADG (g/d). Residual feed intake was calculated using a multiple linear regression model, into which the DMI, ADG, and mid-test metabolic body weight (MBW, as $\mathrm{LBW}^{0.75}$ ) data of all the lambs were introduced. The statistical model used was

$$
\mathrm{Y}_{\mathrm{i}}=\beta_{0}+\beta_{1} \mathrm{MBW}_{\mathrm{i}}+\beta_{2} \mathrm{ADG}_{\mathrm{i}}+\mathrm{e}_{\mathrm{i}},
$$

where $Y_{\mathrm{i}}$ represents the predicted DMI of the ith animal; $\beta_{0}$ is the equation intercept; $\beta_{1}$ is the regression coefficient on MBW; $\beta_{2}$ is the regression coefficient on ADG; and $e_{i}$ is the residual of the ith animal. Then, this prediction may be thought of as the average or expected value for animals of similar weights and rates of gain. The actual daily feed intake minus the predicted feed intake of each individual corresponds to the RFI.

Digestibility was determined using acid insoluble ash as an internal marker. Feed and feces were sampled for $9 \mathrm{~d}$ during the third postweaning period once the animals were completely adapted to being fed the TMR. Samples of offered and refused feed were taken daily from d 1 to 7 of the collection period; daily rectal grab samples were collected once a day before the morning meal for the last $7 \mathrm{~d}$ of the collection period. Samples of both feed and feces of each animal were weighed and pooled to form composite samples and stored at $-30^{\circ} \mathrm{C}$ until acid insoluble ash analysis (Van Keulen and Young, 1977).

The nonslaughtered 24 animals (12 animals per group) were blood sampled for metabolomics analysis early in the morning before TMR distribution when lambs were 8 mo old by jugular venipuncture into tubes containing lithium-heparin, placed in iced water, and centrifuged at $3,520 \times g$ for $16 \mathrm{~min}$ at $5^{\circ} \mathrm{C}$. Then, plasma samples were stored at $-80^{\circ} \mathrm{C}$ until metabolome analyses. Moreover, blood samples were collected 
weekly into tubes containing no anticoagulant. Tubes with no anticoagulant were allowed to clot in a water bath at $37^{\circ} \mathrm{C}$ for $30 \mathrm{~min}$ and then centrifuged at $3,520 \times g$ for $16 \mathrm{~min}$ at $4^{\circ} \mathrm{C}$. Thereafter, serum samples obtained were stored at $-80^{\circ} \mathrm{C}$ until used to measure progesterone concentration. Ovulation was monitored via progesterone assay of weekly blood samples beginning with 4 mo of life until the end of the experiment (9.5 mo old). The measurements were performed on serum by sequential competitive immunoassay (Immulite/Immulite 1000 Progesterone, Siemens Healthcare Diagnostics, Tarrytown, NY).

\section{Metabolomic Profile of Plasma}

A mass spectrometric metabolomics approach was used to profile chemical compounds in plasma samples. Aliquots of each sample $(150 \mu \mathrm{L})$ were diluted in 10 volumes of acetonitrile/methanol/trichloroacetic acid mixture (50:47:3 vol/vol, liquid chromatography/mass spectrometry grade from VWR, Milan, Italy), vortex mixed, and then left at $-18^{\circ} \mathrm{C}$ overnight for protein precipitation. Extracts were then centrifuged $(8,000 \times g)$ at $4^{\circ} \mathrm{C}$ and the supernatant was filtered through a $0.2-\mu \mathrm{m}$ cellulose syringe filter. Analysis of purified extracts was next carried out using ultra-high-performance liquid chromatography coupled to a hybrid quadrupole-timeof-flight mass spectrometer (UHPLC/QTOF-MS). In more detail, an Agilent 1290 liquid chromatograph system equipped with binary pump and a Dual Electrospray Jet Stream ionization system, and an Agilent G6550 mass spectrometer (Agilent Technologies, Santa Clara, CA), were used.

The UHPLC/QTOF-MS metabolomic analysis was carried out as set out in previous experiments (Rouphael et al., 2016). Briefly, compounds were chromatographically resolved on an Agilent Zorbax Eclipse-plus column $(75 \times 2.1 \mathrm{~mm}$ i.d., $1.8 \mu \mathrm{m})$ using a gradient made with $5 \% \mathrm{~B}$ and increased to $90 \% \mathrm{~B}$ within 35 min. Mobile phase consisted of water (A) and methanol (B), flowing at $220 \mu \mathrm{L} / \mathrm{min}$ and $35^{\circ} \mathrm{C}$, whereas the mass spectrometer was run in positive polarity and scan mode (range of 100-1,200 $\mathrm{m} / \mathrm{z}$ ), using a nominal mass resolution of 30,000 full width at half maximum. Electrospray ionization source was set with a capillary voltage of $4 \mathrm{kV}$, a nebulizer pressure of $515,010.4 \mathrm{~Pa}$, and a drying gas (nitrogen) at $280^{\circ} \mathrm{C}$ (Cardarelli et al., 2013).

Postacquisition processing and annotation were done in Profinder B.06 (Agilent Technologies). Compound identification was carried out using accurate masses together with the whole isotopic pattern (i.e., isotope accurate spacing and isotope ratio), following initial deconvolution as well as mass and retention time alignment. Therefore, identification was carried out as level 2 (putatively annotated compounds), according to COSMOS Metabolomics Standards Initiative (http:// cosmos-fp7.eu/msi). The commercially available database Metlin (Agilent Technologies) was used for annotation of compounds. A filter by frequency (retaining those compounds that were present in $75 \%$ of replications within at least one treatment) and by abundance (area >10,000 counts) was finally applied in Mass Profiler Professional B.12.06 (Agilent Technologies).

\section{Statistical Analysis}

Data corresponding to the preweaned slaughtered lambs (organs and noncarcass parts, villus height, liver fat, and TBARS values), together with those related to replacement ewe lamb performance (ADG, RFI, and digestibility) of the nonslaughtered animals, were analyzed by 1-way ANOVA using the GLM procedure of SAS (SAS Institute Inc., Cary, NC) with the dietary treatment (ad libitum or restricted during early life) as the only source of variation. In all cases, the individual lamb was considered as the experimental unit. Significance was declared at $P<0.05$.

Metabolomics data were formerly elaborated using Agilent Mass Profiler Professional B.12.06. Compound abundances were normalized at the 75th percentile and the baseline was set to the median of ADLB animals. Unsupervised hierarchical cluster analysis was carried out setting the similarity measure of Euclidean and Wards as linkage rule. The data set was then exported into SIMCA 13 (Umetrics, Malmo, Sweden), paretoscaled, and elaborated for orthogonal projections to latent structures discriminant analysis (OPLS-DA) supervised modeling. Herein, OPLS-DA allowed separating variation between the groups into predictive and orthogonal (i.e., ascribable to technical and biological variation) components. Outliers were excluded using the distance from the origin in the OPLS-DA model, according to Hotelling's T2 and adopting 95 and $99 \%$ confidence limits for suspect and strong outliers, respectively. Model overfitting was excluded through permutation testing. Model parameters (goodnessof-fit $R^{2} Y$ and goodness-of-prediction $Q^{2} Y$ ) were also produced. Regarding $\mathrm{Q}^{2} \mathrm{Y}$ prediction ability, a value $>0.5$ was adopted as a threshold to identify acceptable models, according to software recommendation and as set out in literature (Rombouts et al., 2017). Variable importance in projection (VIP) analysis was used to evaluate the importance of metabolites and to select those having the highest discrimination potential (VIP score $>1.3$ ). The metabolites highlighted by VIP analy- 
Table 3. Effect of milk replacer restriction during the artificial rearing phase (ad libitum, ADLB, vs. restricted, RES) on visceral organ weights $(\mathrm{g})$, fat depots $(\mathrm{g})$, ileum villi height $(\mu \mathrm{m})$, and liver thiobarbituric acid reactive substance (TBARS) values of preweaned lambs (8 ADLB vs. 8 RES lambs)

\begin{tabular}{|c|c|c|c|c|}
\hline Item & ADLB & RES & $\mathrm{RSD}^{1}$ & $P$-value \\
\hline Birth LBW ${ }^{2}(\mathrm{~kg})$ & 3.94 & 4.21 & 0.318 & 0.111 \\
\hline Slaughter LBW (kg) & 11.1 & 8.06 & 1.09 & $<0.001$ \\
\hline Empty live weight (ELW; kg) & 10.3 & 7.19 & 1.00 & $<0.001$ \\
\hline Total fat depots (TFD; \% of ELW) & 2.81 & 1.54 & 0.405 & $<0.001$ \\
\hline Omental fat (\% TFD) & 33.5 & 18.6 & 5.09 & $<0.001$ \\
\hline Mesenteric fat (\% of TFD) & 33.3 & 51.5 & 8.61 & $<0.001$ \\
\hline Perirenal fat (\% of TFD) & 33.2 & 29.9 & 8.50 & 0.449 \\
\hline Blood (\% of ELW) & 4.25 & 4.42 & 0.576 & 0.563 \\
\hline Liver $(\%$ of ELW) & 2.26 & 2.13 & 0.289 & 0.403 \\
\hline Respiratory tract $^{3}$ (\% of ELW) & 2.56 & 2.54 & 0.196 & 0.866 \\
\hline Heart (\% ELW) & 0.744 & 0.742 & 0.1265 & 0.971 \\
\hline Spleen (\% ELW) & 0.336 & 0.262 & 0.1066 & 0.186 \\
\hline Empty digestive tract $^{4}$ (EDT; \% of ELW) & 9.20 & 9.15 & 0.783 & 0.897 \\
\hline Reticulorumen (\% of EDT) & 9.13 & 11.6 & 2.013 & 0.026 \\
\hline Omasum (\% of EDT) & 1.20 & 2.02 & 1.320 & 0.237 \\
\hline Abomasum (\% of EDT) & 6.92 & 8.32 & 1.445 & 0.071 \\
\hline Small intestine (\% of EDT) & 45.1 & 46.9 & 4.46 & 0.436 \\
\hline Large intestine (\% of EDT) & 17.3 & 19.5 & 3.24 & 0.191 \\
\hline Liver fat (g/kg of DM) & 3.37 & 2.99 & 0.525 & 0.204 \\
\hline Ileum villi height $(\mu \mathrm{m})$ & 523 & 472 & 53.6 & 0.085 \\
\hline Liver TBARS ( $\mu \mathrm{g}$ of $\mathrm{MDA}^{5} / \mathrm{g}$ of sample) & 2.63 & 2.22 & 0.916 & 0.387 \\
\hline \multicolumn{5}{|l|}{${ }^{1}$ Residual standard deviation. } \\
\hline \multicolumn{5}{|l|}{${ }^{2} \mathrm{LBW}=$ live body weight. } \\
\hline \multicolumn{5}{|l|}{${ }^{3}$ Sum of pharynx, trachea, and lungs. } \\
\hline
\end{tabular}

sis were finally analyzed into Mass Profiler Professional for fold-change analysis.

\section{RESULTS}

\section{Visceral Organ Weight, Fat Depots, Histological Structure of Intestinal Mucosa, and Liver Parameters of Preweaned Lambs}

Table 3 summarizes all of the parameters measured in the 35-d-old lambs slaughtered during the MR restriction period. As expected, the RES lambs were slaughtered with a lower LBW (11.1 vs. $8.06 \mathrm{~kg}$ for ADLB and RES lambs, respectively; $P<0.001$ ). Consequently, to obtain information about body development regardless of the LBW at slaughter, we decided to express all the weights as percentage of empty live weight, percentage of the empty digestive tract (EDT), or percentage of total fat depots. According to our results, only those parameters related to the development of several part of the gastrointestinal tract were affected by early feed restriction. Thus, although the weights of the reticulorumen and abomasum were reduced for the RES lambs $(P<0.001$, data not shown), the proportion of these parts of the gut was increased when calculated as percentage of the EDT. In addition, average villus height was greater $(P<0.05)$ in ileal epithelium of ADLB compared with RES lambs (523 vs. $472 \mu \mathrm{m}$, Table 3). Moreover, the proportion of omental fat (expressed as percentage of total fat depots) was significantly reduced in the RES lambs, whereas an opposite effect was observed for the mesenteric fat weight. No differences in liver fat or liver antioxidant status (TBARS) were observed between both groups of lambs $(P>0.05)$.

\section{Animal Performance of Replacement Ewe Lambs}

Animal performance data can be found in Table 4 . As expected, ADG during the suckling period was reduced for the RES ewe lambs (116 vs. $237 \mathrm{~g} / \mathrm{d}, P<$ 0.001 ), so the age at weaning was delayed slightly to avoid hampering the viability of this group of animals. Once weaned, the ADG during the first postweaning period was higher for the RES lambs (274 vs. $238 \mathrm{~g} / \mathrm{d}$, $P=0.029)$ while they were being fed the starter feed together with alfalfa hay and barley straw. Thereafter, once the replacement ewe lambs were being fed the TMR, RES ewe lambs showed reduced ADG $(P<0.05)$ in the second postweaning period. No differences in the RFI, feed-to-gain ratio, or digestibility parameters $(P$ $>0.05)$ were detected during this third postweaning 


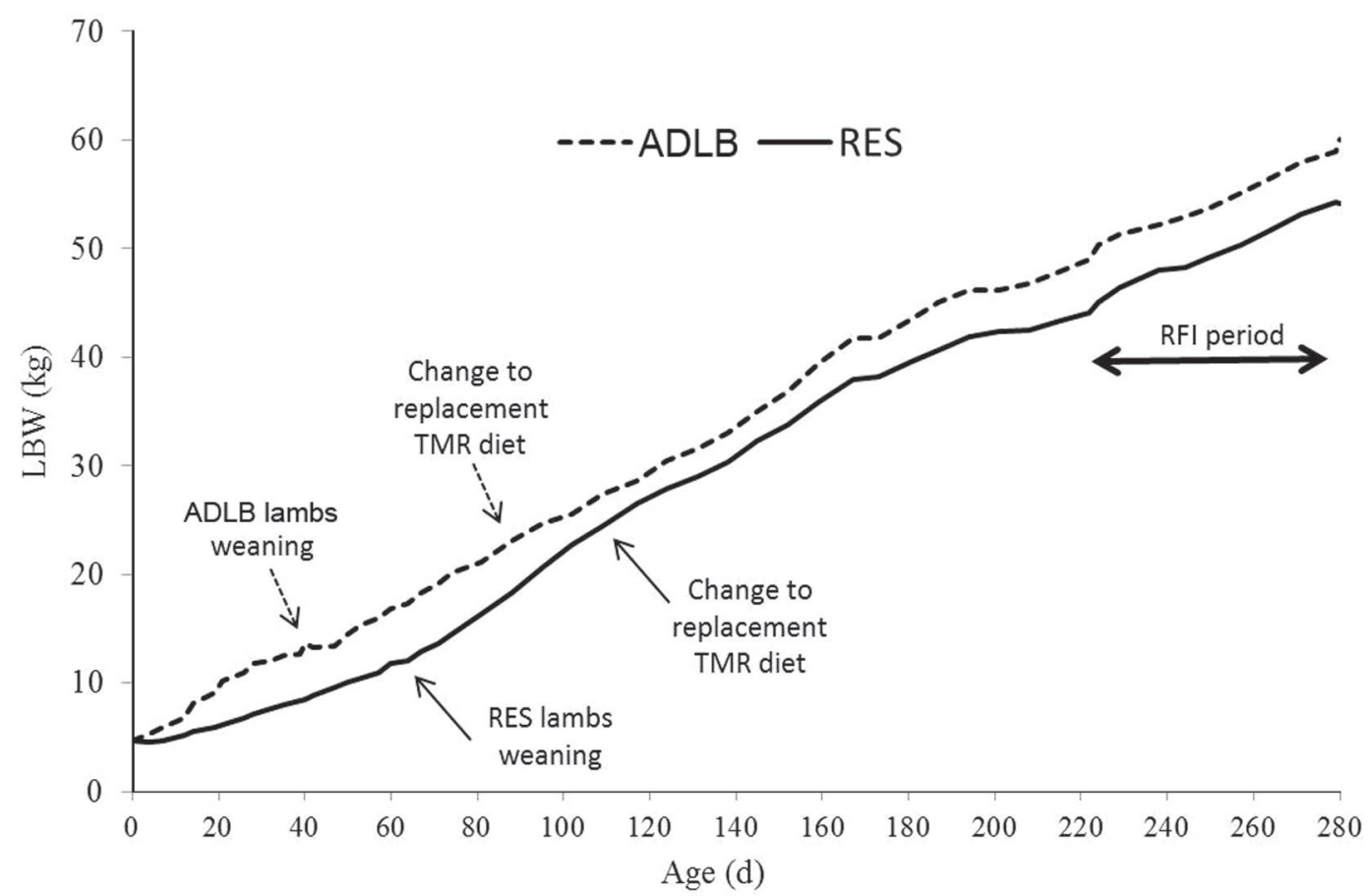

Figure 1. Change of live body weight (LBW, $\mathrm{kg}$ ) throughout the experiment of replacement ewe lambs that received ad libitum (ADLB) or restricted (RES) feed during the artificial rearing phase. RFI = residual feed intake.

Table 4. Effect of milk replacer restriction during the artificial rearing phase (ad libitum, ADLB, vs. restricted, RES) on pre- and postweaning growth performance of replacement ewe lambs (12 ADLB vs. 12 RES lambs)

\begin{tabular}{lcccr}
\hline Item & ADLB & RES & RSD & $P$-value \\
\hline Birth LBW L $^{1}$ (kg) & 4.69 & 4.72 & 0.531 & 0.894 \\
Suckling period & & & & \\
ADG suckling period (g/d) & 237 & 116 & 48.9 & $<0.001$ \\
LBW at beginning of weaning (kg) & 13.7 & 11.2 & 0.62 & 0.002 \\
LBW at weaning (kg) & 13.4 & 12.1 & 0.43 & 0.002 \\
Age at weaning (d) & 47 & 65 & 10.6 & $<0.001$ \\
First postweaning period & 238 & 274 & 38.6 & 0.029 \\
ADG first PW period (g/d) & 89 & 107 & 10.7 & $<0.001$ \\
Age at the end of first PW period (d) & 23.4 & 23.8 & 1.58 & 0.612 \\
LBW at the end of first PW period (kg) & & & & \\
Second postweaning period & 202 & 182 & 21.1 & 0.049 \\
ADG at second PW period (g/d) & 224 & 224 & 2.8 & 0.666 \\
Age at the end of second PW period (d) & 50.4 & 45.1 & 7.62 & 0.101 \\
LBW at the end of second PW period (kg) & & & & \\
Third postweaning period (RFI estimation) & 178 & 158 & 32.3 & 0.146 \\
ADG at third PW period (g/d) & 280 & 280 & 2.8 & 0.666 \\
Age at the end of third PW period (d) & 60.1 & 54.1 & 7.87 & 0.087 \\
LBW at the end of third PW period (kg) & 1,779 & 1,652 & 243.2 & 0.212 \\
DMI third PW period (g of DM/animal per d) & -2.02 & 0.603 & 143.4 & 0.968 \\
RFI (g of DM/animal per d) & 10.1 & 10.4 & 1.46 & 0.897 \\
Feed-to-gain ratio (g of DMI/g of ADG) & 67.4 & 66.5 & 4.83 & 0.669 \\
DM digestibility (\%) & 69.4 & 68.6 & 4.69 & 0.699 \\
OM digestibility (\%) & & &
\end{tabular}

${ }^{1}$ Residual standard deviation.

${ }^{2} \mathrm{LBW}=$ live body weight.

${ }^{3} \mathrm{PW}=$ postweaning.

${ }^{4}$ Residual feed intake (RFI) calculated using ADG estimated by regression. 


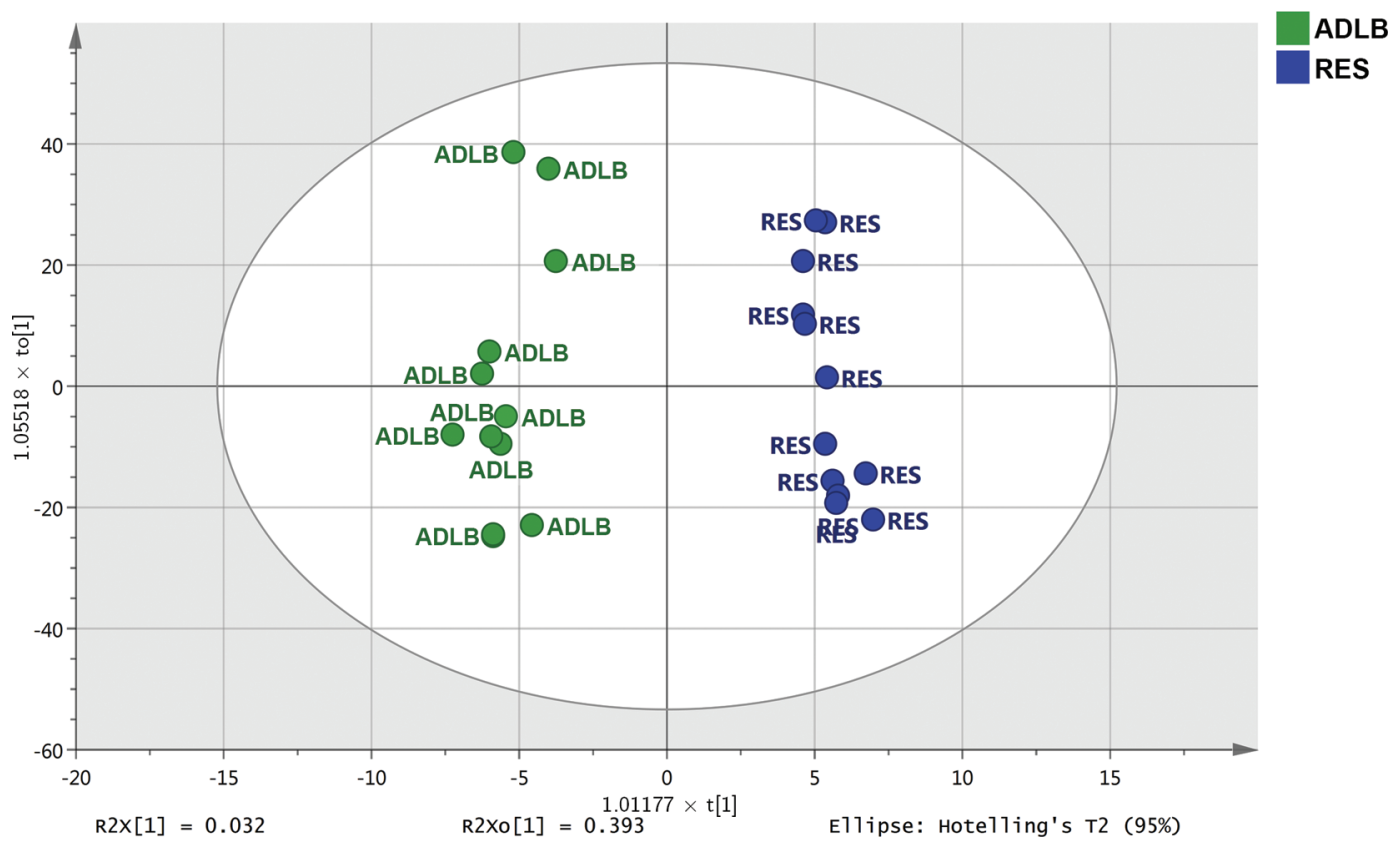

Figure 2. Plasma samples from replacement ewe lambs that received ad libitum (ADLB) or restricted (RES) feed during the artificial rearing phase, analyzed for metabolomic profile and distributed in the score plot according to the first 2 components of the model (i.e., to and t1, these items being preceded by values scaling each component proportionally to the percentage of variance explained). R2X[1] and R2Xo[1] represent the variation explained by each component (nonorthogonal and orthogonal component, respectively). Results were produced by the software SIMCA 13 (Umetrics, Malo, Sweden). Color version available online.

period, but a trend $(P=0.087)$ was observed toward reduced $\mathrm{LBW}(\mathrm{kg})$ at the end of the experiment for the RES ewe lambs (Figure 1).

\section{Metabolomic Profile}

With regard to the metabolomic profile obtained when the ewe lambs were 8 mo old, this procedure successfully classified the plasma samples into 2 different clusters related to the experimental treatments (ADLB and RES, Figure 2). The OPLS-DA supervised approach allowed to effectively separate the 2 treatments, resulting in a goodness-of-fit $R^{2} Y$ of 0.84 and a prediction ability $\mathrm{Q}^{2} \mathrm{Y}$ of 0.55 . The model was validated by cross-validated ANOVA and resulted in a 100\% classification after misclassification test. Hotelling's T2, carried out at both 95 and 99\% (suspect and strong outliers, respectively), excluded the presence of outlier samples. Given the validity of the supervised model, VIP analysis allowed to point out differential metabolites. These latter were finally subjected to fold-change analysis; these compounds, together with their trend in RES versus ADLB treatments, are provided in Table 5. In total, 129 metabolites with a VIP score $>1.3$ were detected, 48 of them being identified with the database used. From this set of compounds, 42 metabolites were over-accumulated and 6 down-accumulated in the RES when compared with the ADLB lambs. Most of the metabolites over-accumulated in the RES group were related to lipids such as diacylglycerophosphoinositols [e.g., PI (15:0/14:0)], diacylglyceropyrophosphates \{e.g., PPA [16:0/18:1(9Z)]\}, or diacylglycerophosphates \{e.g., PA [20:5(5Z,8Z,11Z,14Z,17Z)/21:0]\}, but also to protein metabolism (e.g., 2-oxoarginine, Ne-methylL-lysine, Thr Phe Arg), xenobiotics (e.g., vomicine), inflammation [e.g., prostaglandin $\mathrm{E}_{2}\left(\mathbf{P G E}_{2}\right)$-biotin], or apoptosis \{e.g., monoacylglycerophosphoserines, PS $[17: 1(9 Z) / 0: 0]\}$.

\section{Serum Levels of Progesterone}

In this study, the first ovulation was determined based on serum progesterone levels of $0.4 \mathrm{ng} / \mathrm{mL}$ or greater (Quirke et al., 1985; Wright et al., 2002). According to the pattern of serum progesterone, and considering the whole experimental period (from birth to 9.5 mo old), 4 ewe lambs of the ADLB group evidenced a first ovulation when they were $194 \pm 36.1 \mathrm{~d}$ old versus only 1 animal ( $235 \mathrm{~d}$ old) from the RES group.

\section{DISCUSSION}

The present study was designed to quantify the effect of MR restriction (suckling phase) on animal perfor- 
Table 5. List of identified metabolites (variable importance in projection, VIP, score $>1.3$ ) differentially accumulated in plasma samples from restricted replacement ewe lambs (RES) when compared with those fed ad libitum (ADLB) during the artificial rearing phase

\begin{tabular}{|c|c|c|c|}
\hline Metabolite & $\begin{array}{c}\text { VIP } \\
\text { score }\end{array}$ & $\log _{2} \mathrm{FC}^{1}$ & Regulation $^{2}$ \\
\hline \multicolumn{4}{|l|}{ Lipid metabolites $^{3}$} \\
\hline PA $[18: 4(6 Z, 9 Z, 12 Z, 15 Z) / 14: 1(9 Z)]$ & 1.421 & 5.227 & $\mathrm{Up}$ \\
\hline $\mathrm{PA}[18: 4(6 \mathrm{Z}, 9 \mathrm{Z}, 12 \mathrm{Z}, 15 \mathrm{Z}) / 18: 3(6 \mathrm{Z}, 9 \mathrm{Z}, 12 \mathrm{Z})]$ & 1.387 & 3.344 & Up \\
\hline $\mathrm{PA}[18: 3(9 \mathrm{Z}, 12 \mathrm{Z}, 15 \mathrm{Z}) / 15: 1(9 \mathrm{Z})]$ & 1.320 & 0.062 & Up \\
\hline $\mathrm{PE}(20: 0 / 0: 0)$ & 1.692 & -5.218 & Down \\
\hline $\mathrm{PG}[18: 3(9 \mathrm{Z}, 12 \mathrm{Z}, 15 \mathrm{Z}) / 18: 2(9 \mathrm{Z}, 12 \mathrm{Z})]$ & 1.775 & 0.256 & Up \\
\hline PG [18:3(9Z,12Z,15Z)/15:1(9Z)] & 1.609 & 0.088 & Up \\
\hline$P G[21: 0 / 20: 3(8 \mathrm{Z}, 11 \mathrm{Z}, 14 \mathrm{Z})]$ & 1.371 & 3.172 & Up \\
\hline $\mathrm{PG}[22: 2(13 \mathrm{Z}, 16 \mathrm{Z}) / 0: 0]$ & 1.313 & 0.014 & Up \\
\hline PI $(15: 0 / 14: 0)$ & 2.156 & 0.204 & Up \\
\hline PI [18:0/18:3(6Z,9Z,12Z)] & 1.701 & 0.335 & Up \\
\hline PI $[18: 4(6 Z, 9 Z, 12 Z, 15 Z) / 18: 0]$ & 1.487 & 3.398 & Up \\
\hline $\mathrm{MG}[0: 0 / 24: 1(15 \mathrm{Z}) / 0: 0]$ & 1.576 & 0.091 & Up \\
\hline Taurocholic acid & 1.723 & 3.927 & Up \\
\hline Cimicifetiside A & 1.787 & 0.171 & Up \\
\hline Minabeolide-8 & 1.643 & 6.579 & Up \\
\hline Triacetin & 1.428 & 0.271 & Up \\
\hline 3-Propylmalic acid & 1.446 & 0.259 & Up \\
\hline 10-Nitrooleate & 1.380 & 0.025 & Up \\
\hline \multicolumn{4}{|l|}{ Vitamin D metabolism } \\
\hline (5E)-(24R)-24,25-dihydroxy-(6,19,19-trideutrio) vitamin $\mathrm{D}_{3}$ & 1.497 & 3.019 & Up \\
\hline $1 \alpha, 25$-dihydroxy-26,27-dimethyl-24a-homo-22-thia-20-epivitamin $\mathrm{D}_{3}$ & 1.381 & 3.304 & Up \\
\hline 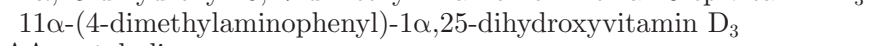 & 1.308 & 0.038 & Up \\
\hline \multicolumn{4}{|l|}{ AA metabolism } \\
\hline Ne-Methyl-L-lysine & 1.726 & 0.426 & Up \\
\hline \multicolumn{4}{|l|}{ Phenolic compounds } \\
\hline Trihydroxycoprostanoic acid & 1.715 & 0.291 & Up \\
\hline Vomicine & 1.569 & 0.098 & Up \\
\hline Acacetin 7-(4"-acetylrutinoside) & 1.368 & 0.382 & Up \\
\hline Thalicoside A & 1.301 & 0.338 & Up \\
\hline \multicolumn{4}{|l|}{ Other metabolites } \\
\hline Guanine & 1.744 & -2.194 & Down \\
\hline Glycosyl-4,4'-diaponeurosporenoate & 1.985 & 10.192 & Up \\
\hline Avermectin A2a monosaccharide & 1.345 & 4.556 & Up \\
\hline Avocadene acetate & 1.716 & 4.546 & Up \\
\hline UDP-D-apiose ${ }^{4}$ & 1.377 & -0.113 & Down \\
\hline
\end{tabular}

${ }^{1} \mathrm{FC}=$ fold change.

${ }^{2}$ Analysis were done considering RES versus ADLB; hence, "up" means the compound is overaccumulated in RES as compared with the ADLB group.

${ }^{3} \mathrm{PA}=$ diacylglycerophosphates; $\mathrm{PE}=$ monoacylglycerophosphoethanolamines; $\mathrm{PG}=$ diacylglycerophosphoglycerols; PI $=$ diacylglycerophosphoinositols; PPA = diacylglyceropyrophosphates; PS = monoacylglycerophosphoserines; MG = monoacylglycerols.

${ }^{4}$ UDP-D-apiose = uridine 5'-diphosphate-D-apiose. 
mance and progesterone patterns during the replacement period of ewe lambs to elucidate the mechanisms responsible for the effects promoted by a metabolome approach. This is relevant because the intake of MR can be reduced on farm due to unhealthy status of the lambs, environmental conditions (e.g., hot weather during the summer; good/bad barn hosting the lambs), or inadequate management of the artificial MR, thus lowering profitability during postweaning phases.

Similar to other studies under feed restriction conditions (Drouillard et al., 1991; dos Santos et al., 2016), the RES preweaned lambs were slaughtered with a lower LBW, which explains the reduced weight of all the organs and carcass or noncarcass components registered at slaughter (data not shown). However, it must be stressed that the proportion of several parts of the gut (e.g., reticulorumen and abomasum) was increased when calculated as a percentage of the EDT, whereas the average villus height in the ileal epithelium was shorter in the RES preweaned lamb. This is in agreement with the results obtained by Greenwood et al. (2004), who observed at a similar LBW (20 kg) that slowly reared lambs (low nutrition) had a larger stomach complex than those reared ad libitum. Our previous experiments in fattening lambs (Santos et al., 2018b) have demonstrated that all these morphological changes can persist at a LBW of $27 \mathrm{~kg}$, thus 3 mo later after having finished the period of feed restriction. However, the experimental period of the present study was extended much longer, which might have had consequences on the morphology of the gut, as will be explained below.

Moreover, as expected, the RES replacement ewe lambs grew up more slowly during the suckling period as a consequence of commercial MR restriction. Once weaned, a compensatory growth period was observed for the RES group (first postweaning period) while they were being fed the starter feed (more energetic) together with alfalfa hay and barley straw administered in separate feeders. During this phase, ADLB ewe lambs were supposed to be depositing fat, whereas the weight gain of RES ewe lambs was probably composed mainly by protein and muscle due to a temporary reduction of their adipose tissue during the feed restriction period (Berge, 1991; Hornick et al., 2000); this fact, together with the lower maintenance energy requirements during the compensatory growth period as a consequence of a lower LBW (Saubidet and Verde, 1976) would help to explain the higher ADG of RES ewe lambs during the first postweaning period. A second explanation for the compensatory growth might be related to an increased DMI of RES lambs during this phase. In any case, RES animals were older at the end of the first postweaning period (identical LBW for both groups) because LBW differences did not disappear totally after compensatory growth (Hornick et al., 2000).

Thereafter, in accordance with other studies (Davies and Owen, 1967; Galvani et al., 2014), ADG of the RES group was decreased during the second postweaning period, when the replacement ewe lambs were being fed the TMR with no chance to select the ingredients in different feeders. At this point, the greater forestomachs (and probably slower rate of passage) or the different growth of the gut regions caused by early feed restriction might have reduced DMI in the RES ewe lambs (Berge, 1991; Greenwood and Cafe, 2007). This reduced ADG might have been enhanced in RES ewe lambs due to an increased fat deposition once the compensatory growth period was finished (Berge, 1991; Hornick et al., 2000).

However, the lack of effects on ADG, RFI, feed-togain ratio, or apparent digestibility parameters during the third postweaning period suggests that the plasticity of the gut might have corrected, at least partially, the morphological changes after several months of being fed a TMR rich in fiber (Chilliard et al., 1998). Moreover, Berge (1991) and Hennessy and Arthur (2004) described that FE is little affected in the long term by nutrition before weaning due to the progressive reduction of differences in the composition of body gain during the refeeding period. However, regardless of the lack of effects on FE during this last postweaning phase, the RES replacement ewe lambs showed reduced LBW at the end of the experimental period as a clear sequel of early feed restriction, which limited the capacity to exhibit compensatory growth and achieve equivalent weight for age in later life (Allden, 1979; Berge, 1991; Hornick et al., 2000; Greenwood and Cafe, 2007).

Furthermore, the metabolomic profile was performed to understand the mechanisms under the sequels of early feed restriction. Accordingly, this approach revealed that many metabolites related to lipid metabolism were over-accumulated in the RES ewe lambs. However, as previously stated, a higher fat accretion was not supposed to take place during the third postweaning period of RES ewe lambs, so these metabolites might be indicating other alterations different from fat accretion (Berge, 1991). In this sense, the over-accumulation in the RES group of phosphatidylserine compounds [e.g., PS (17:1(9Z)/0:0), PS (19:1(9Z)/12:0), which are involved in fundamental processes of apoptosis] and $\mathrm{PGE}_{2}$-biotin (one of the most abundant metabolites of arachidonic acid) is remarkable. These metabolites are indicators of intracellular stress and inflammatory response of the RES replacement ewe lambs (Ricciotti and FitzGerald, 2011; Vance and Guergana, 2013), which might has been caused by the over-accumulation of several alkaloids (e.g., vomicine), flavonoids [e.g., 
acacetin 7-(4"-acetylrutinoside)], triterpenes (e.g., trihydroxycoprostanoic acid), and bile acid metabolites (e.g., taurocholic acid) with cytotoxic effects (Trevisi et al., 2012).

Moreover, the increased accumulation of $\mathrm{PGE}_{2}$-biotin in RES animals (a structural analog of $\mathrm{PGE}_{2}$ ) detected by the metabolome profile could also have implications on reproductive function because an apparent prerequisite for ovulation in sheep is a major accumulation of $\mathrm{PGF}_{2 \alpha}$ with respect to $\mathrm{PGE}_{2}$ during the later phase of the preovulatory period (Murdoch and Farris, 1988). Therefore, the higher levels of $\mathrm{PGE}_{2}$ might have delayed the first ovulation in the RES replacement ewes lambs. With this regard, the establishment of the age of puberty was not one of the aims of the present study because these animals born at the end of August were expected to remain prepubertal until the short days in the following autumn (Corner-Thomas et al., 2015), much later after the end of the experimental phase $(9.5$ mo old, at the beginning of June). However, the progesterone levels measured along the whole experiment revealed that 5 replacement ewes had ovulated for the first time (4 ADLB vs. 1 RES), even though they failed to initiate regular cyclicity (regular progesterone levels greater than $0.4 \mathrm{ng} / \mathrm{mL}$ ) and estrus exhibition. Moreover, the RES replacement ewe lamb reaching the first ovulation was older ( $235 \mathrm{~d}$ ) than the 4 ADLB ewes (194 $\pm 36.1 \mathrm{~d}$ ), which suggests a delay in the first ovulation (Robinson et al., 2002, 2005).

\section{CONCLUSIONS}

Under these experimental conditions, FE of replacement ewe lambs was not impaired by moderated MR restriction during early life. However, the lower LBW and the different progesterone levels at the end of the experimental period suggest the existence of long-term effects caused by early feed restriction. Therefore, future experiments should clarify the effects of early feed restriction on the reproductive traits (e.g., puberty, conception, fertility, and prolificity rates), subsequent lactations, or FE of the progeny of these Assaf replacement ewe lambs, and also the mechanisms underlying any detrimental consequence found to design strategies to correct it.

\section{ACKNOWLEDGMENTS}

This work was supported by the Spanish Ministry of Economy, Industry and Competitiveness (MINECO, AGL2014-54124R). Alba Santos gratefully acknowledges receipt of a predoctoral grant from the Spanish Ministry of Education, Culture and Sport (MECD,
FPU15/01630). We also thank Consejo Superior de Investigaciones Científicas (CSIC; Proyecto Intramural Especial; Project 201540E084) and University of León (Ayudas Puente Formativas) for supporting J. Frutos. The authors gratefully thank Julio Benavides (Instituto de Ganadería de Montaña, CSIC-Universidad de León) for providing histological sections of intestinal samples. The authors declare no conflicts of interest.

\section{REFERENCES}

Allden, W. G. 1979. Undernutrition of the Merino sheep and its sequelae. V.* The influence of severe growth restriction during early post-natal life on reproduction and growth in later life. Aust. J. Agric. Res. 30:939-948. https://doi.org/10.1071/AR9790939.

AOAC International. 2003. Official Methods of Analysis of the Association of Official Analytical Chemists. 17th ed. AOAC International, Gaithersburg, MD.

Bell, A., and P. Greenwood. 2016. Nutrition during gestation influences postnatal productivity of ruminant livestock. Feedipedia, Broadening Horizons. No. 30.

Berge, P. 1991. Long-term effects of feeding during calfhood on subsequent performance of beef cattle (a review). Livest. Prod. Sci. 28:179-201. https://doi.org/10.1016/0301-6226(91)90142-D.

Bodas, R., N. Prieto, M. J. Jordán, O. López-Campos, F. J. Giráldez, L. Morán, and S. Andrés. 2012. The liver antioxidant status of fattening lambs is improved by naringin dietary supplementation at $0.15 \%$ rates but not meat quality. Animal 6:863-870. https://doi .org/10.1017/S175173111100214X.

Cardarelli, M., Y. Rouphael, E. Rea, L. Lucini, M. Pellizzoni, and G. Colla. 2013. Effects of fertilization, arbuscular mycorrhiza, and salinity on growth, yield, and bioactive compounds of two Aloe species. HortScience 48:568-575.

Carrillo, J. A., Y. He, Y. Li, J. Liu, R. A. Erdman, T. S. Sonstegard, and J. Song. 2016. Integrated metabolomic and transcriptome analyses reveal finishing forage affects metabolic pathways related to beef quality and animal welfare. Sci. Rep. 6:25948. https://doi .org/10.1038/srep25948.

Chilliard, Y., F. Bocquier, and M. Doreau. 1998. Digestive and metabolic adaptations of ruminants to undernutrition, and consequences on reproduction. Reprod. Nutr. Dev. 38:131-152. https://doi .org/10.1051/rnd:19980201.

Corner-Thomas, R. A., A. L. Ridler, S. T. Morris, and P. R. Kenyon. 2015. Ewe lamb live weight and body condition scores affect reproductive rates in commercial flocks. N. Z. J. Agric. Res. 58:26-34. https://doi.org/10.1080/00288233.2014.974766.

Davies, D. A. R., and J. B. Owen. 1967. The intensive rearing of lambs 1 . Some factors affecting performance in the liquid feeding period. Anim. Sci. 9:501-508. https://doi.org/10.1017/ S0003356100042070.

dos Santos, A. A., P. G. Pimentel, E. S. Pereira, G. R. Moreira, J. A. D. Barbosa Filho, I. Y. Izubuti, E. L. A. Ribeiro, and D. L. Sousa. 2016. Carcass and non-carcass components of Santa Ines lambs subjected to food restriction. Semin. Cienc. Agrar. 37:947-958. https://doi.org/10.5433/1679-0359.2016v37n2p947.

Drackley, J. K., B. C. Pollard, H. M. Dann, and J. A. Stamey. 2007. First-lactation milk production for cows fed control or intensified milk replacer programs as calves. J. Dairy Sci. 90(Suppl. 1):614. (Abstr.)

Drouillard, J. S., T. J. Klopfenstein, R. A. Britton, M. L. Bauer, S. M. Gramlich, T. J. Wester, and C. L. Ferrell. 1991. Growth, body composition, and visceral organ mass and metabolism in lambs during and after metabolizable protein or net energy restrictions. J. Anim. Sci. 69:3357-3375. https://doi.org/10.2527/1991 $.6983357 x$.

Galvani, D. B., C. C. Pires, C. H. Hübner, S. Carvalho, and T. P. Wommerd. 2014. Growth performance and carcass traits of early- 
weaned lambs as affected by the nutritional regimen of lactating ewes. Small Rumin. Res. 120:1-5. https://doi.org/10.1016/j .smallrumres.2014.03.008.

Giráldez, F. J., P. Frutos, P. Lavín, and A. R. Mantecón. 1999. Body composition changes and energy retention in milk-fed lambs undergoing energy restriction. Small Rumin. Res. 31:127-133. https:// doi.org/10.1016/S0921-4488(98)00129-1.

Gotoh, T. 2015. Potential of the application of epigenetics in animal production. Anim. Prod. Sci. 55:145-158. https://doi.org/10 .1071/AN14467.

Greenwood, P. L., and L. M. Cafe. 2007. Prenatal and pre-weaning growth and nutrition of cattle: long-term consequences for beef production. Animal 1:1283-1296. https://doi.org/10.1017/ S175173110700050X.

Greenwood, P. L., A. S. Hunt, and W. Bell. 2004. Effects of birth weight and postnatal nutrition on neonatal sheep: IV. Organ growth. J. Anim. Sci. 82:422-428. https://doi.org/10.2527/2004 $.822422 \mathrm{x}$.

Hennessy, D. W., and P. F. Arthur. 2004. The effect of preweaning growth restriction on the feed intake and efficiency of cattle on a grain-based diet before slaughter. Aust. J. Exp. Agric. 44:483-488. https://doi.org/10.1071/EA02110.

Hornick, J. L., C. Van Eenaeme, O. Gérard, I. Dufrasne, and L. Istasse. 2000. Mechanisms of reduced and compensatory growth. Domest. Anim. Endocrinol. 19:121-132. https://doi.org/10.1016/ S0739-7240(00)00072-2.

ISO. 1999. Animal feeding stuffs - Determination of moisture and other volatile matter content. ISO 6496:1999. International Organization for Standardization, Geneva, Switzerland.

ISO. 2002. Animal feeding stuffs - Determination of crude ash. ISO 5984:2002. International Organization for Standardization, Geneva, Switzerland.

ISO. 2005. Animal feeding stuffs-Determination of nitrogen content and calculation of crude protein content, Kjeldahl method. ISO 5983:2005. International Organization for Standardization, Geneva, Switzerland.

Kaske, M., S. Wiedemann, and H.-J. Kunz. 2010. Metabolic programming. Background and potential impact for dairy cattle. Vlaams Diergen. Tijds. 79:445-451.

Koch, R. M., L. A. Swiger, D. Chambers, and K. E. Gregory. 1963. Efficiency of feed use in beef cattle. J. Anim. Sci. 22:486-494.

Makovicky, P., E. Tumova, Z. Volek, P. Makovicky, and P. Vodicka. 2014. Histological aspects of the small intestine under variable feed restriction: The effects of short and intense restriction on a growing rabbit model. Exp. Ther. Med. 8:1623-1627. https://doi.org/ 10.3892/etm.2014.1924.

Murdoch, W. J., and M. L. Farris. 1988. Prostaglandin $\mathrm{E}_{2}-9$-ketoreductase activity of preovulatory ovine follicles. J. Anim. Sci. 66:29242929. https://doi.org/10.2527/jas1988.66112924x.

Neto, S. G., L. R. Bezerra, A. N. Medeiros, M. A. Ferreira, E. C. Pimenta Filho, E. P. Cândido, and R. L. Oliveira. 2011. Feed restriction and compensatory growth in Guzerá females. Asianaustralas. J. Anim. Sci. 24:791-799. https://doi.org/10.5713/ajas .2011.10417.

NRC. 1985. Nutrient Requirements of Sheep. 6th ed. National Academy Press, Washington, DC.

Quirke, J. F., G. H. Stabenfeldt, and G. E. Bradford. 1985. Onset of puberty and duration of the breeding season in Suffolk, Rambouillet, Finnish Landrace, Dorset and Finn-Dorset ewe lambs. J. Anim. Sci. 60:1463-1471. https://doi.org/10.2527/jas1985.6061463x.
Ricciotti, E., and G. A. FitzGerald. 2011. Prostaglandins and inflammation. Arterioscler. Thromb. Vasc. Biol. 31:986-1000. https:// doi.org/10.1161/ATVBAHA.110.207449.

Robinson, J. J. 1996. Nutrition and reproduction. Anim. Reprod. Sci. 42:25-34. https://doi.org/10.1016/0378-4320(96)01526-6.

Robinson, J. J., C. J. Ashworth, J. A. Rooke, L. M. Mitchell, and T. G. McEvoy. 2005. Nutrition and fertility in ruminant livestock. Anim. Feed Sci. Technol. 126:259-276. https://doi.org/10.1016/j .anifeedsci.2005.08.006.

Robinson, J. J., J. A. Rooke, and T. G. McEvoy. 2002. Nutrition for conception and pregnancy. Pages 189-211 in Sheep Nutrition. M. Freer and H. Dove, ed. CABI Publishing, Wallingford, UK.

Rombouts, C., L. Y. Hemeryck, T. Van Hecke, S. De Smet, W. H. De Vos, and L. Vanhaecke. 2017. Untargeted metabolomics of colonic digests reveals kynurenine pathway metabolites, dityrosine and 3-dehydroxycarnitine as red versus white meat discriminating metabolites. Sci. Rep. 7:42514. https://doi.org/10.1038/srep42514.

Rouphael, Y., J. Bernardi, M. Cardarelli, L. Bernardo, D. Kane, G. Colla, and L. Lucini. 2016. Phenolic compounds and sesquiterpene lactones profile in leaves of nineteen artichoke cultivars. J. Agric. Food Chem. 64:8540-8548. https://doi.org/10.1021/acs.jafc $.6 \mathrm{~b} 03856$.

Santos, A., F. J. Giráldez, J. Mateo, J. Frutos, and S. Andrés. 2018a. Programming Merino lambs by early feed restriction reduces growth rates and increases fat accretion during the fattening period with no effect on meat quality traits. Meat Sci. 135:20-26. https://doi.org/10.1016/j.meatsci.2017.08.007.

Santos, A., F. J. Giráldez, E. Trevisi, L. Lucini, J. Frutos, and S. Andrés. 2018c. Liver transcriptomic and plasma metabolic profiles of fattening lambs are modified by feed restriction during the suckling period. J. Anim. Sci. 96:1495-1507. https://doi.org/10 $.1093 /$ jas $/$ sky029.

Santos, A., C. Valdés, F. J. Giráldez, S. López, J. France, J. Frutos, M. Fernández, and S. Andrés. 2018b. Feed efficiency and the liver proteome of fattening lambs are modified by feed restriction during the suckling period. Animal 1-9. https://doi.org/10.1017/ S1751731118000046.

Saubidet, C. L., and L. S. Verde. 1976. Relationship between live weight, age and dry-matter intake for beef cattle after different levels of food restriction. Anim. Prod. 22:61-69. https://doi.org/ 10.1017/S000335610003542X.

Trevisi, E., M. Amadori, S. Cogrossi, E. Razzuoli, and G. Bertoni. 2012. Metabolic stress and inflammatory response in high-yielding, periparturient dairy cows. Res. Vet. Sci. 93:695-704. https://doi .org/10.1016/j.rvsc.2011.11.008.

Van Keulen, J., and B. A. Young. 1977. Evaluation of acid-insoluble ash as natural marker in ruminant digestibility. J. Anim. Sci. 44:282-287. https://doi.org/10.2527/jas1977.442282x.

Vance, J. E., and T. Guergana. 2013. Formation and function of phosphatidylserine and phosphatidylethanolamine in mammalian cells. Biochim. Biophys. Acta 1831:543-554. https://doi.org/10.1016/j .bbalip.2012.08.016.

Wright, C., A. C. Evans, N. P. Evans, P. Duffy, J. Fox, M. P. Boland, J. F. Roche, and T. Sweeney. 2002. Effect of maternal exposure to the environmental estrogen, octylphenol, during fetal and/or postnatal life on onset of puberty, endocrine status, and ovarian follicular dynamics in ewe lambs. Biol. Reprod. 67:1734-1740. https:// doi.org/10.1095/biolreprod.101.002006. 